\title{
Structural and Optical Characterisation of Hydrogenated Soda-Lime Silicate Glasses Doped with Silver and Copper
}

\author{
M. Suszyńska, L. Krajczyk and B. Macalik \\ Institute of Low Temperature and Structure Research \\ Polish Academy of Sciences, 50-950 Wrocław, P.O. Box 1410, Poland \\ (Received August 18, 2003; revised version November 27, 2003)

\begin{abstract}
The results of comparative studies of the effect of hydrogenation upon
\end{abstract} \\ structural and optical properties of the commercial soda-lime silicate glasses \\ doped either with monovalent silver or copper have been presented. The sam- \\ ples were characterised by means of the scanning and transmission electron \\ microscopy and the UV-VIS-IR absorption spectroscopy. It has been shown \\ that the annealing of suitably ion-exchanged specimens in gaseous hydrogen \\ atmosphere could be considered as an effective procedure for obtaining com- \\ posite materials of expected properties correlated with the induced changes \\ of the morphology of both the glassy matrix and the dopant.
}

PACS numbers: 61.43.Fs, 64.75.+g, 68.37.Lp, 78.20.-e, 78.40.Ha

\section{Introduction}

During the last years, composite glasses containing nanoclusters of either noble or transition metals have been raised a lot of interest owing to their potential optical applications. The nonlinear optical susceptibility and the picosecond response time at high excitation intensities of such composites are comparable with that characteristic of crystalline materials [1-3]. For this reason, it is of fundamental importance to develop processes that allow controlling the size, shape, concentration and distribution of the metal-clusters inside the glassy matrix.

Preliminary investigations of commercial multicomponent soda-lime silicate (SLS) glasses exchanged either with monovalent silver or copper have shown that the structure-sensitive properties of such materials could be affected by both the microstructure of the glassy matrix and the peculiar behaviour of the quantum dots related with the dopants $[4-7]$. 
One of the most used tools for investigation of such systems is the optical absorption (OA) spectroscopy. The surface plasmon resonance band (its shape and position), exhibited by the embedded metal nanoclusters, give information on the structure and distribution of the nanoclusters as well as on dielectric functions of the metal and matrix forming the composite. Transmission electron microscopy (TEM)-observations are also of great importance for studies of the doped SLS glasses.

To obtain an insight into the processes which control the structure-sensitive properties of SLS glasses exchanged either with silver or copper ions, OA-measurements were accompanied by TEM-observations and selected area electron diffraction (SAED) as well as high resolution transmission electron microscopy (HRTEM) analysis. The aim of the work described was to compare the effect of hydrogenation upon the microstructure and optical absorption of doped SLS glasses of different origin.

\section{Samples and experiments}

Two types of commercial multicomponent SLS glasses, the composition of which corresponds to the miscibility-gap in the $\mathrm{SiO}_{2}-\mathrm{Na}_{2} \mathrm{O}$ system [8], have been used. The main components of both glasses were as follows (in mole \%): $\mathrm{SiO}_{2} / 74$, $\mathrm{Na}_{2} \mathrm{O} / 13, \mathrm{CaO} / 6.4$, and $\mathrm{MgO} / 4.5$. Different glass-making procedures resulted in slightly different contents of the $\mathrm{Al}, \mathrm{Fe}, \mathrm{Mn}$, and $\mathrm{K}$ ions in glasses of type I (prepared as $1 \mathrm{~mm}$-thick sheets) and II (prepared as $5 \mathrm{~mm}$-thick plates). Optical characteristics of these materials in the as-prepared state are shown in Fig. 1. Glasses

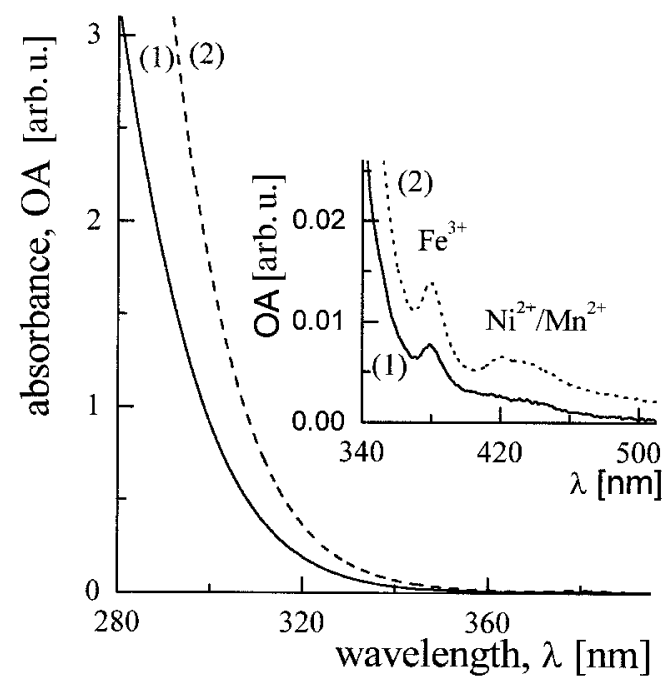

Fig. 1. The optical absorption of SLS glasses I (curve 1) and II (curve 2) in the UV spectral range; the inset shows absorption related to the dopants (Fe) and impurities $(\mathrm{Ni} / \mathrm{Mn})$ present in these glasses. 
of type I with less potassium and no manganese have been exchanged with silver ions, whereas glasses of type II gave the copper-exchanged composites.

The ion-exchange procedure comprised dipping of the host matrix in the respective metal salt bath. Either molten $\mathrm{AgNO}_{3}$ at $670 \mathrm{~K}$ or $\mathrm{Cu}_{2} \mathrm{Cl}_{2}$ at temperatures between $720 \mathrm{~K}$ and $940 \mathrm{~K}$ for different time intervals have been used; for more detail see $[6,7]$. The copper was also introduced by employing the $\mathrm{CuCl}_{2}$ bath. The concentration of exchanging ions inside the glass-matrices was monitored by the Philips scanning microscope (SEM 515) with a roentgenographic analyser (EDAX 9800) working at $20 \mathrm{kV}$. Penetration profiles of the sodium, silver, and copper ions inside the glasses of type I and II are shown in Figs. 2 and 3, respectively. In the case of the copper-exchanged glasses of type II, the character of the profile depends on the exchange temperature but not on the type of the salt-bath $\left(\mathrm{Cu}_{2} \mathrm{Cl}_{2}\right.$ or $\left.\mathrm{CuCl}_{2}\right)$ used for the exchange process. Also hydrogenation of samples is not changing the qualitative character of the penetration profiles.

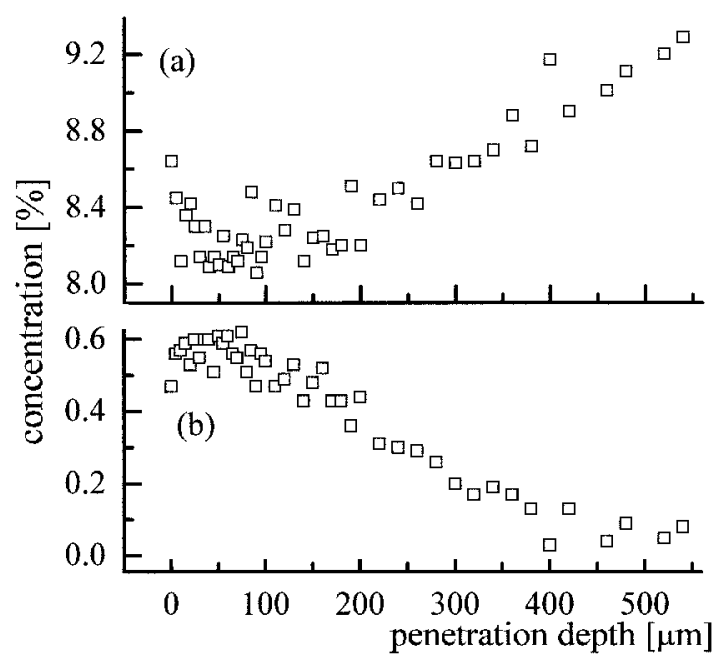

Fig. 2. Concentration of the sodium (part a) and silver (part b) ions versus their penetration depth in glasses of type I.

After ion exchange, the specimens have been annealed in a continuous stream of dry hydrogen at temperatures ranging between $373 \mathrm{~K}$ and $773 \mathrm{~K}$ at the atmospheric pressure. In a typical experiment, the sample was firstly flushed with hydrogen at room temperature (RT) for $30 \mathrm{~min}$. Then, it was heated in the hydrogen (heating rate was between $6 \mathrm{deg} / \mathrm{min}$ and $20 \mathrm{deg} / \mathrm{min}$ ) up to the required temperature. The annealing time ranges between $1 \mathrm{~min}-50 \mathrm{~h}$. After hydrogenation, the samples were either quenched or slowly cooled to RT without passivation.

Some of the silver-exchanged and hydrogenated glasses have been deformed in a home-made apparatus [9]. The sample was driven at different velocities (1500- 


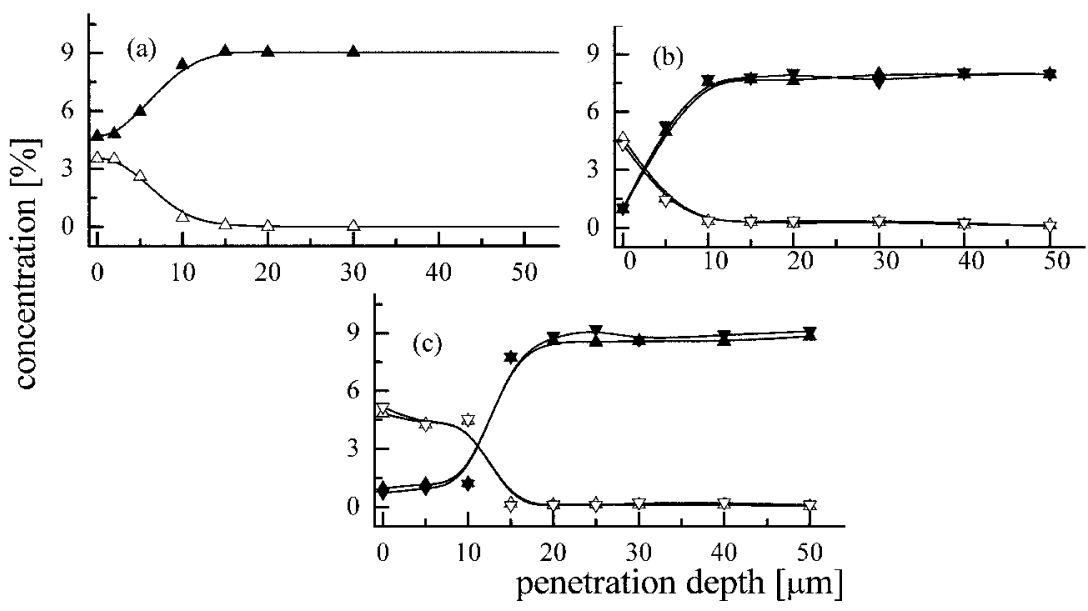

Fig. 3. Concentration of copper $(\Delta, \nabla)$ and sodium (full $\Delta$, full $\nabla$ ) versus their penetration depths in samples II exchanged at $723 \mathrm{~K}$ (part a), $833 \mathrm{~K}$ (part b), and $943 \mathrm{~K}$ (part c) with monovalent copper, respectively. The up- and down-triangles correspond to the data taken for two surfaces of the exchanged samples.

$200 \mu \mathrm{m} / \mathrm{min}$ ) through a narrow heating zone (about $37-\mathrm{mm}$ long) at $873 \mathrm{~K}$ under a constant load equal to $98 \mathrm{~N}$.

Optical absorption of the glass-samples was measured at RT in the range between 250 and $2500 \mathrm{~nm}$ by using a Varian (Carry 5E) spectrophotometer. For the deformed samples linearly polarised light in a direction parallel or perpendicular to the tensile axis was used.

For electron microscopy studies a transmission electron microscope (TEM, Philips-CM 20) was used at $200 \mathrm{kV}$ with $0.24 \mathrm{~nm}$ point-to-point resolution. Shadowed carbon- and extraction-replicas have been prepared from sample surfaces selectively etched in diluted water solutions of HF. The HRTEM and SAED analysis accomplished the TEM-studies.

\section{Results and discussion}

\subsection{Phase separation}

It has been stated that glasses of type $\mathbf{I}$ are separated into two phases with a remarkable difference in the chemical durability. This phase-separation probably occurs already during the glass-making procedure. Their etching was possible with rather weak (hydrofluoric acid (HF) + water)-solutions. From shadows of the replicated surfaces it was inferred that the composition of the dispersed phase is low silica, whereas that of the matrix phase is the high silica one. The separated particles have been tentatively ascribed to $\mathrm{Na}_{2} \mathrm{O}$-rich particles. After hydrogenation secondary phase separation phenomena were detected, and the new elements of the glass structure were etched together with the originally separated phase 
suggesting that both are of comparable chemical durability and probably also of similar composition.

The glass of type II was separated into phases with a less pronounced difference in the chemical durability, and stronger $\left(\mathrm{HF}+\mathrm{H}_{2} \mathrm{O}\right)$-solutions were required for their etching. The difference in the chemical durability of both SLS glasses could be the consequence of the differences in chemical composition of the phases and in technological parameters of the glass-making procedures. Moreover, the presence of $\mathrm{K}_{2} \mathrm{O}$ probably retards the phase separation similar to the effect observed for coloration of these glasses [10].

\subsection{Structural characteristics obtained from transmission electron microscopy}

For the sake of clarity, the TEM-observations are presented as first, since they show directly the structural changes, which could affect the OA data of the doped SLS glasses.

Figures 4 and 5 present typical sets of TEM-micrographs of the carbon replicas obtained for specimens I. There are shown the matrix morphology (Fig. 4) and the behaviour of silver (Fig. 5) in these glasses after hydrogenation (parts b in both figures) and after deformation (parts b and d in both figures). Annealing
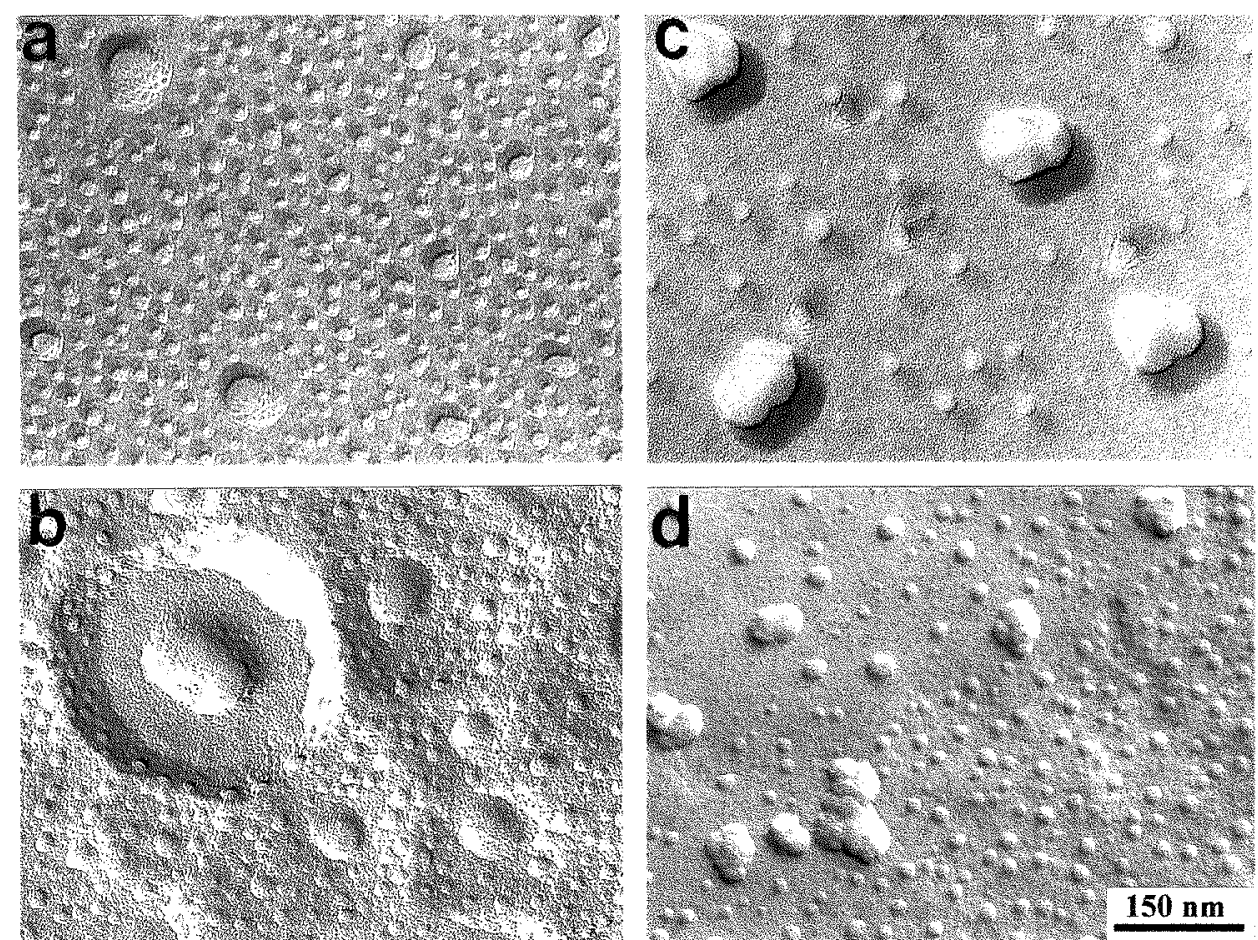

Fig. 4. Characteristic TEM-micrographs of etched glasses I. The matrix-morphology is shown for not deformed (left column) and deformed (right column) samples in the as-prepared state (part a) and after hydrogenation (parts b-d). 

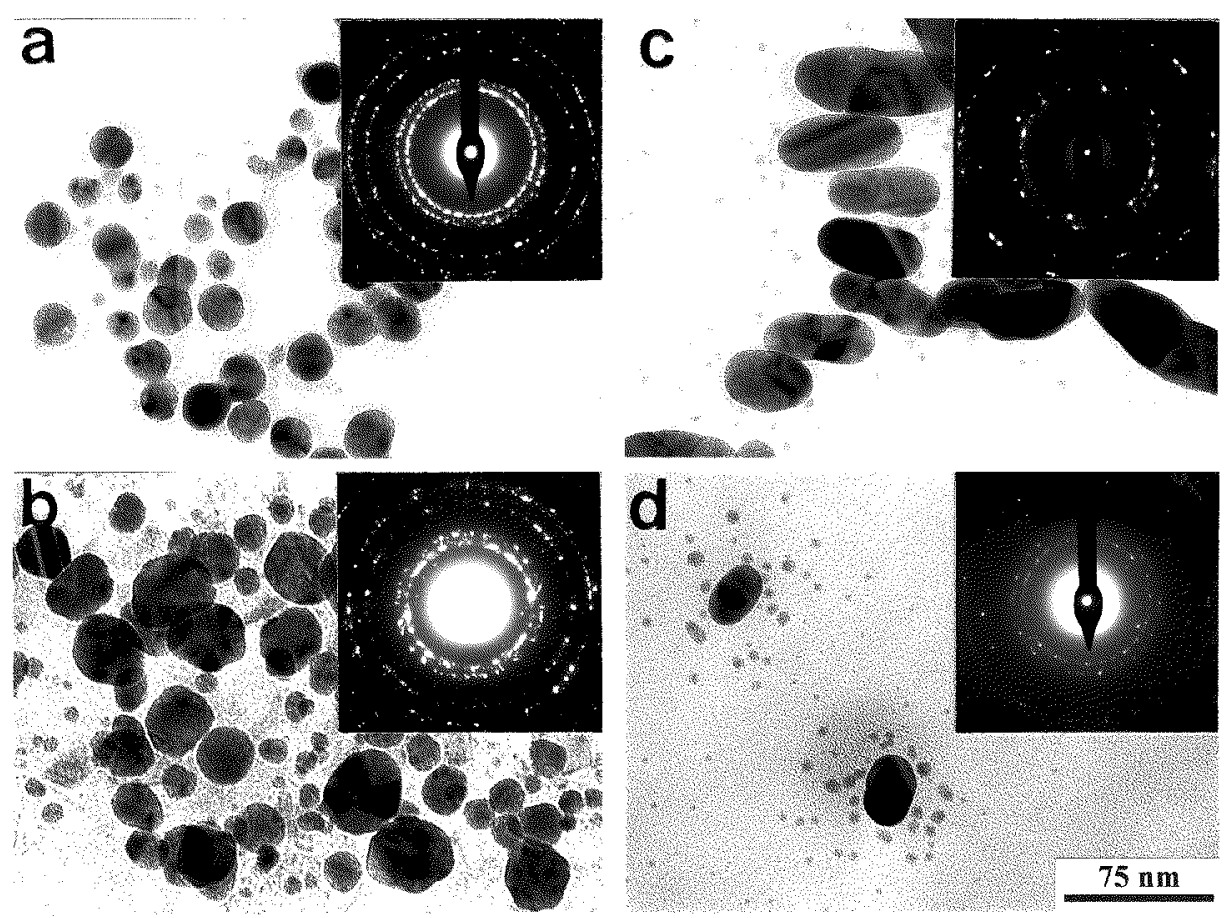

Fig. 5. Characteristic TEM-micrographs of etched glasses I. Silver particles are shown for not deformed (left column) and deformed (right column) samples in the as-prepared state (part a) and after hydrogenation (parts b-d). The insets present electron diffraction patterns related to silver particles, the shape, quantity, and size, which are different in samples treated in a different way.

in hydrogen yields an increase in size of $\mathrm{Na}_{2} \mathrm{O}$-rich droplets, the secondary phase separation and reduction of the silver ions to atoms. Subsequent diffusion of these atoms leads to the formation of spherical Ag-nanoparticles. Their size increases with annealing at $T \geq 670 \mathrm{~K}$, probably as a consequence of the Ostwald ripening.

Especially interesting are the effects of deformation of these specimens. The largest silver particles become elongated in the direction of the sample-tension, whilst the smallest remain not deformed in the surrounding of the deformed ones. The stretching affects particles with a diameter larger than $5 \mu \mathrm{m}$, interpreted as a threshold size, at least for the stresses used in the described work. This bimodal size-distribution and the change of spherical silver particles into prolate spheroids imply new applications of such composites.

For the copper-doped and hydrogenated glasses II, the particles are of various shapes and size (see Fig. 6). The smallest particles are nearly of equal size and spherical in shape, while the largest are irregular in shape and exhibit the presence of many stacking faults. According to the electron diffraction pattern, 

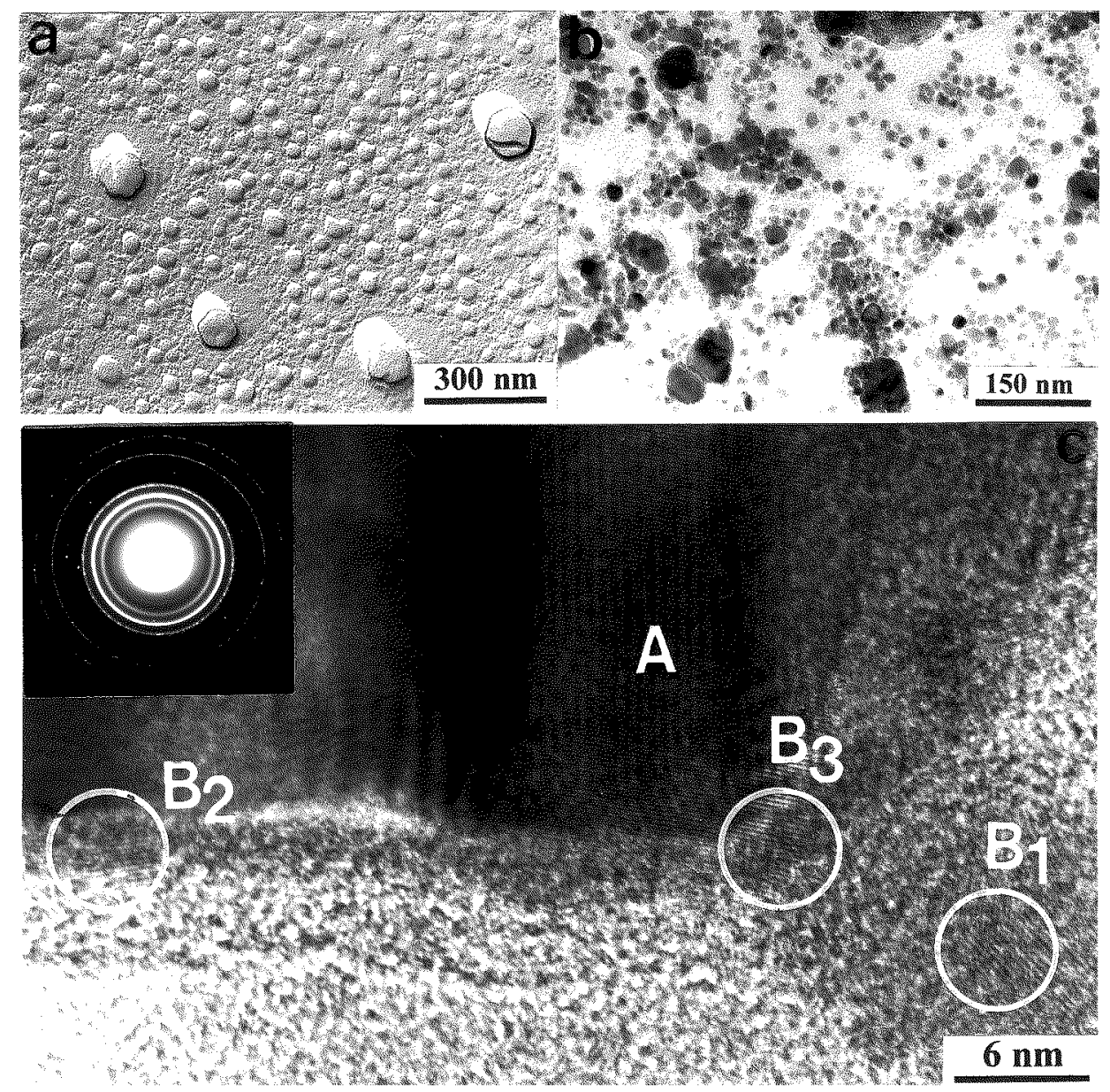

Fig. 6. TEM-micrographs of the etched surfaces of glass II exchanged with copper. The matrix morphology (part a), copper-nanoparticles (part b) and the HRTEM-picture (part c) with the lattice elements of crystalline $\mathrm{Cu}$ - and $\mathrm{Cu}_{2} \mathrm{O}$-nanoparticles are shown.

crystalline $\mathrm{Cu}$ - and $\mathrm{Cu}_{2} \mathrm{O}$-particles have been evidenced in these specimens. The small particles entirely correspond to $\mathrm{Cu}_{2} \mathrm{O}$, see the fringes $\mathrm{B}_{1} / 0.302 \mathrm{~nm}$ related to (110) planes and the $\mathrm{B}_{2} / 0.247 \mathrm{~nm} /(111)$ ones. The largest particles are composed of the metallic $\mathrm{Cu}$-core, see fringes $\mathrm{A} / 0.209 \mathrm{~nm} /(111)$, surrounded by a layer of semiconducting $\mathrm{Cu}_{2} \mathrm{O}$, see fringes $\mathrm{B}_{2} / 0.247 \mathrm{~nm} /(111)$ and $\mathrm{B}_{3} / 0.214 \mathrm{~nm} /(200)$. It seemed reasonably to suppose that the colloidal Cu-particles formed during hydrogenation are highly reactive with respect to the surrounding air-atmosphere. According to our knowledge, this is the first evidence of the formation of colloidal $\mathrm{Cu}_{2} \mathrm{O}$ nanoparticles in ion-exchanged SLS glasses. This could be interesting for studies of the quantum confinement effects that are expected when the nanopar- 
ticles are small enough. Moreover, preparation of semiconducting-nanostructures in a glassy matrix can be exploited for obtaining novel glass-ceramic materials.

\subsection{Optical absorption spectra of the microstructurally anisotropic glasses}

Optical absorption spectra of the ion-exchanged and annealed glasses I and II are shown in Figs. 7 and 8 . There are shown the spectra of as-prepared (curves 1 in both figures) and hydrogenated (curves 3-5 in Fig. 7 and curves 2-5 in Fig. 8) samples. In the latter case, the OA bands are located at about $420 \mathrm{~nm}$ and at about $560 \mathrm{~nm}$. These bands correspond to the surface-plasmon resonance of the Ag- and Cu-particles, respectively $[11,12]$. With an increase in annealing $T$, the absorption related with the copper and silver nanoparticles showed a blue shift, which can be attributed to the change in particle size and/or volume fraction.

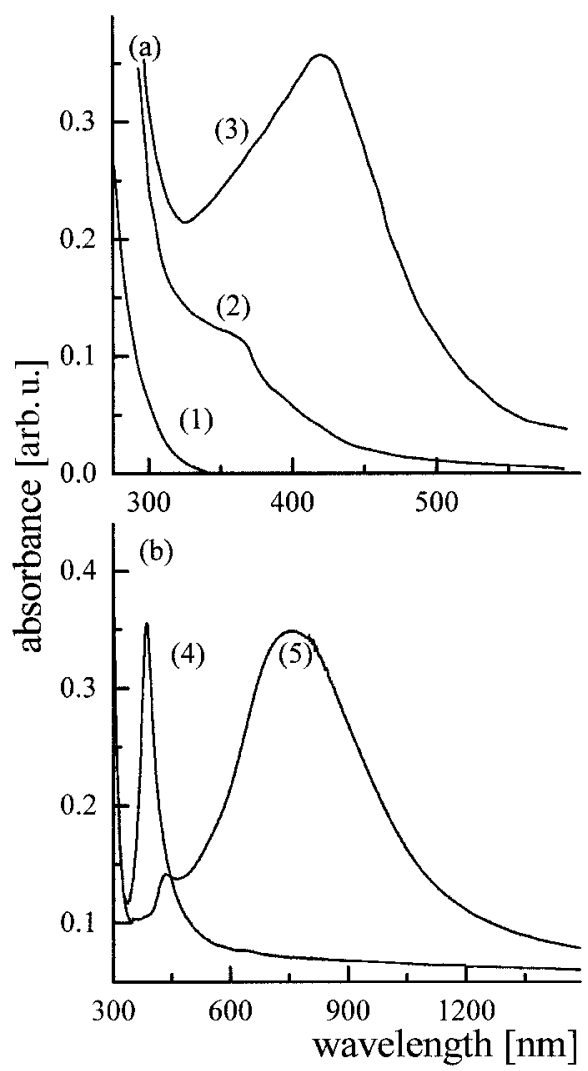

Fig. 7. Optical absorption spectra of glasses I in as-prepared (curve 1), exchanged with silver (curve 2), hydrogenated after exchange (curve 3), and deformed after exchange and hydrogenation (curves 4, 5) states. The $370 \mathrm{~nm}$-shoulder (see curve 2) relates to the presence of atomic silver. For the deformed samples light polarised either perpendicular (curve 4) or parallel (curve 5) to the tensile axis was employed. 


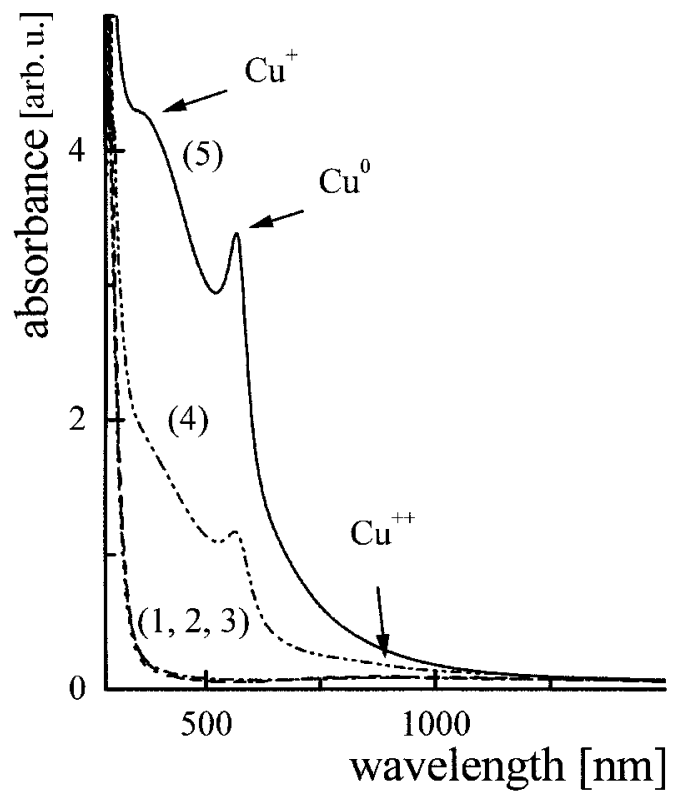

Fig. 8. Optical absorption spectra of glasses II exchanged with monovalent copper at $723 \mathrm{~K}$ and isochronally $(5 \mathrm{~h})$ annealed in a hydrogen atmosphere. Curves $1,2,3,4$, and 5 correspond to as-prepared (1), annealed at $373 \mathrm{~K}(2), 473 \mathrm{~K}(3), 573 \mathrm{~K}$ (4), and $673 \mathrm{~K}(5)$ samples, respectively.

Figure 7 (part a) shows optical absorption of the SLS glasses of type I before the ion exchange (curve 1), after exchange (curve 2), and after hydrogenation (curve 3 ). In the last case, the $420 \mathrm{~nm}$-band is characteristic of the spherical silver colloids yielding a yellow-brownish coloration of the glasses. The silver-species are characterised by the band-position $(\lambda)$, the area under the band (giving the concentration) and the particle diameter $(2 R)$ obtainable from the empirical relation between $\lambda$ and the half-width of the absorption band $\left(\delta_{1 / 2}\right)$ [13]. It has been found that the diameter of the nanosized $\mathrm{Ag}$-particles is between 2 and $11 \mathrm{~nm}$ increasing with the distance from the exchanged surface.

The part $\mathrm{b}$ of Fig. 7 gives the OA spectra induced by deformed silver nanoparticles and measured with light linearly polarised in a direction parallel (curve 5) and perpendicular (curve 4) to the tensile axis. The separation of the detected bands increases by increasing the deformation degree, i.e. by increasing the eccentricity of the prolate spheroidal silver particles. Moreover, for samples annealed in hydrogen a doubling of the long $\lambda$-band into two Lorentzian components occurs, suggesting some periodical size and/or shape changes (modulations) of the particles. The weaker band, located at the shorter wavelength, could be related to the small spherical silver particles, which are not affected by deformation; see the results of TEM-observations. 
To interpret the OA-spectra of copper (Fig. 8), one has to emphasise that after exchange, copper in the SLS glasses is present in the form of cuprous $(+1)$ and cupric $(+2)$ ions. Only the cupric ions create colour centres with a broad absorption band (at about $780 \mathrm{~nm}$ ) inducing the blue/green colour of the glasses. The shift of the fundamental absorption edge towards lower energies is probably due to the presence of an absorption band related with cuprous ions. Hydrogenation of samples at $T \geq 570 \mathrm{~K}$ results in the formation of atomic copper in a surface layer whose thickness increases with time and temperature of hydrogenation. The copper nanoparticles induce a red/ruby colour of samples, and this colour is related to the nonsymmetrical absorption band located at about $560 \mathrm{~nm}$ due to the surface plasmon resonance of the colloidal metal nanoparticles [11]. The evolution of this band with increasing reduction time and/or temperature reflects the changes in size of these particles. The broad absorption band, located at the high-energy side of the colloidal- $\mathrm{Cu}^{2+}$-band has been attributed to the presence of nanosized $\mathrm{Cu}_{2} \mathrm{O}$ particles shown by TEM observations. According to our knowledge, it is the first evidence of the formation of colloidal $\mathrm{Cu}_{2} \mathrm{O}$-nanoparticles in the SLS-glass matrix. It could be interesting for studies of the quantum confinement effects that are expected when the semiconducting-particles are small enough.

\section{Concluding remarks}

Combined optical absorption and electron microscopy studies demonstrated that the colour changes of doped SLS glasses are controlled by the initial reduction of the dopant-ions to the atomic state and by subsequent diffusion of the atoms to the growing nuclei which increase in size with the time of treatment. The extraordinarily strong polarizability of the metal clusters at the surface plasmon frequency could result in marked nonlinear properties of such composites.

The presence of a secondary phase separation in these glasses instead of a partial devitrification, characteristic of prolonged application of electric field [14] or irradiation [15], suggests that the permeation of hydrogen allows not only the reduction of the dopant but also affects the glass-network. However, the formation of free hydroxyl ions, suggested in the literature, e.g. [16], was not evidenced. Instead, it seems be reasonable to assume that the oxidation of monovalent copper ions inside the matrix and/or at the glass-surface is of great importance. During reaction of the type: $2 \mathrm{Cu}^{+}+2 \mathrm{Na}^{+}+$"oxygen" $\Rightarrow 2 \mathrm{Cu}^{++}+\mathrm{Na}_{2} \mathrm{O}$, new amorphous $\mathrm{Na}_{2} \mathrm{O}$ particles arise giving the secondary phase separation detected by TEM observations. For confirmation of this hypothesis, further work is necessary.

The step-like penetration profile, detected for suitably copper-exchanged glasses, and the deformation-induced dichroism of the optical absorption of the glasses containing colloidal silver particles could be exploited for new applications, especially in the field of integrated optics. 


\section{Acknowledgments}

The work was performed in the frame of the the State Committee for Scientific Research project no. 7T 08D 06021. The authors wish to thank Dr K.J. Berg, from the Physics Department, University of Halle, Germany, for the preparation of the deformed samples.

\section{References}

[1] F. Hache, D. Ricard, C. Flytzanis, U. Kreibig, Appl. Phys. A 47, 347 (1988).

[2] R.A. Myers, N. Mukherjee, S.R.S. Bruek, Opt. Lett. 16, 1937 (1991).

[3] R.F.Jr. Haglund, L. Yang, R.H. Magruder III, C.W. Whute, R.A. Zuhr, L. Yang, R. Dorsinville, R.R. Alfano, Nucl. Instrum. Methods B 91, 493 (1994).

[4] K.J. Berg, R. Capelletti, L. Krajczyk, M. Suszyńska, in: Proc. Intern. Symp. on Electrets (ISE 10), Delphi (Greece) 1999, Eds. A.A. Konsta, A. Vassilikou-Dova, K. Vartzelli-Nikaki (available from IEEE Dielectric and Electrical Insulation Society, 1999, p. 411).

[5] M. Suszyńska, M. Szmida, P. Grau, Mater. Sci. Eng. A 319-321, 702 (2001).

[6] B. Macalik, L. Krajczyk, J. Okal, T. Morawska-Kowal, K.D. Nierzewski, M. Suszyńska, Radiat Eff. Defects Solids 157, 888 (2002).

[7] K.J. Berg, P. Grau, M. Petzold, M. Suszyńska, in: Proc. XII Intern. Confer. on Defects in Insulating Materials, Eds. O. Kanert, J.M. Spaeth, World Scientific, Singapore 1993, p. 611.

[8] E.A. Porai-Koshits, V.J. Averjanov, J. Non-Crystal. Solids 1, 29 (1965).

[9] W.G. Drost, Ph.D. Thesis, Halle (Germany) 1992.

[10] M. Suszynska, B. Macalik, T. Morawska-Kowal, E. Okuno, E.M. Yoshimura, E. Yukihara, Radiat Eff. Defects Solids 156, 353 (2001).

[11] U. Kreibig, M. Vollmer, in: Optical Properties of Metal Clusters, Vol. 25, Springer-Verlag, Berlin 1995, p. 79.

[12] C. Estournes, N. Cornu, J.L. Guille, J. Non-Crystal. Solids 170, 287 (1994).

[13] M. Menning, K.J. Berg, Mater. Sci. Eng. 81, 133 (1985).

[14] K.-J. Berg, R. Capeletti, L. Krajczyk, M. Suszynska, in: Proc. 9th Intern. Symp. on Electrets (ISE 9), Shanghai (China) 1996, Eds. X. Zhongfu, Z. Hongyan (available from IEEE Dielectric and Electrical Insulation Society, 1996, p. 378).

[15] T. Morawska-Kowal, L. Krajczyk, B. Macalik, K.D. Nierzewski, E. Okuno, M. Suszynska, M. Szmida, E.M. Yoshimura, Nucl. Instrum. Methods B 166/167, $490(2000)$.

[16] J.E. Shelby, J. Appl. Phys. 51, 2589 (1980). 